\title{
Rippling muscle disease
}

INSERM

\section{Source}

INSERM. (1999). Orphanet: an online rare disease and orphan drug data base. Rippling muscle disease. ORPHA:97238

Rippling muscle disease is a rare, genetic, neuromuscular disorder characterized by muscle hyperirritability triggered by stretch, percussion or movement. Patients present wave-like, electrically-silent muscle contractions (rippling), muscle mounding, painful muscle stiffness and muscle hypertrophy, usually with elevated serum creatine kinase. 